\title{
Effect of genotype on changes in intelligence quotient after dietary relaxation in phenylketonuria and hyperphenylalaninaemia
}

Lindsey G Greeves, Christopher C Patterson, Dennis J Carson, Ruth Thom, Melanie C Wolfenden, Johannes Zschocke, Colin A Graham, Norman C Nevin, Elisabeth R Trimble
Royal Belfast Hospital for Sick Children, Belfast BT12 6BE, UK L G Greeves

E R Trimble

Department of Dietetics, The Royal Belfast Hospital for Sick Children R Thom

Department of Clinical Psychology, Royal Belfast Hospital for Sick Children

M C Wolfenden

Department of Epidemiology and Public Health, Queen's University of Belfast, Belfast BT12 6BN, UK C C Patterson

Department of Child Health, Queen's

University of Belfast

D J Carson

Department of Medical Genetics, Belfast City Hospital, Belfast BT9 7AB, UK

J Zschocke

C A Graham

N C Nevin

Correspondence to: Professor E R Trimble, Department of Clinical Biochemistry, Royal Victoria Hospital, Grosvenor Road, Belfast, BT12 6BA, UK

Accepted 22 October 1999

\begin{abstract}
Background-Associations between genotype and intellectual outcome in patients with phenylketonuria are complicated because intelligence is influenced by many variables, including environmental factors and other genetic determinants. Intellectual changes with age, both on and after relaxation of diet, vary within the patient population. This study aims to determine whether a significant association exists between genotype and change in intelligence after relaxation of diet.

Methods-125 patients with hyperphenylalaninaemia and phenylketonuria whose diet was relaxed after 8 years of age. Verbal, performance, and full scale intelligence quotients at 8,14 , and 18 years were expressed as standard deviation scores (IQ-SDS), and genotype as predicted residual enzyme activity (PRA) of phenylalanine hydroxylase.

Results-IQ-SDS at 8, 14, and 18 years were significantly below normal; no association was found between PRA and IQ-SDS. Significant reductions in verbal and full scale IQ-SDS occurred between 8 and 14 years and 8 and 18 years. There was a significant association between PRA and the reduction in verbal, performance, and full scale IQ between these years. Multiple regression analysis of 18 year results, using 8 year results as covariates, supported the association between PRA and IQ-SDS; after adjustment for phenylalanine control, both up to and after the age of 8 years, the full scale IQ-SDS at 14 and 18 years was 0.15 higher for each $10 \%$ increase in PRA.
\end{abstract}

Conclusions-Genotype might be useful in predicting the likelihood of intellectual change in patients with hyperphenylalaninaemia and phenylketonuria whose diet is relaxed after the age of 8 years.

(Arch Dis Child 2000;82:216-221)

Keywords: mutation; predicted residual enzyme activity; phenylketonuria; intelligence quotient

The success of the clinical management of patients with phenylketonuria and hyperphenylalaninaemia is undoubtedly best judged by intellectual outcome. The importance of dietary control in the early years of life is universally recognised. ${ }^{1-9}$ The necessity for strict dietary control in the later years is less clear, and has led to much controversy, with most recent studies tending to highlight the adverse effects of dietary relaxation or discontinuation. ${ }^{26}{ }^{9-25}$ However, it has been noted that reduction in IQ scores in children who discontinue the diet does not occur in all cases, and can also be seen in those who continue the diet. ${ }^{1218}{ }^{26}$ In fact, one study found that $40 \%$ of patients gained IQ points or maintained their previous IQ level after discontinuation of diet at 5 years of age. ${ }^{18}$ So far, it has not been possible to predict which patients will do well intellectually if diet is relaxed or discontinued.

The development of molecular genetics has led to the identification of numerous mutations of the phenylalanine hydroxylase gene. Mutations vary in their effect on the enzymatic activity of phenylalanine hydroxylase. A predicted residual enzyme activity (PRA) has been determined from in vitro measurements for many of these mutations, and has been found to differ for each mutation. ${ }^{27-30}$ It is unlikely that there is a simple relation between genotype and intelligence per se, because environmental factors and other genetic influences might modulate the in vivo expression of the phenylalanine hydroxylase gene, ${ }^{31-33}$ and also because of intrinsic intellectual endowment unrelated to the phenylalanine hydroxylase locus. Therefore, studies of intelligence and genotype, some of which have expressed genotype quantitatively as PRA, ${ }^{31}{ }^{34}$ have been inconclusive and have tended to suggest that there is not a direct association between genotype and intellectual outcome. ${ }^{31}{ }^{34-36}$ However, the influence of environmental and genetic factors other than that of the phenylalanine hydroxylase mutation can be reduced substantially by considering the change in IQ over a period of time in the same patient in relation to genotype.

The aim of this study was to assess the intellectual outcome in patients diagnosed by Guthrie screening attending the regional clinic in our hospital, and to determine whether there was a significant association between intellectual change with age and genotype (expressed as PRA) for phenylalanine hydroxylase in a group of patients whose diet was relaxed at 8 years of age.

\section{Methods}

We studied all patients with phenylketonuria and hyperphenylalaninaemia attending the regional centre who were born between 1969 and 1986 and identified by neonatal screening. 
The following variables were considered: IQs, gender, father's social class at diagnosis, age diagnostic venous sample was taken and/or diet commenced, number of days from birth until whole blood phenylalanine concentration was reduced to $500 \mu \mathrm{mol} /$ litre or less, dietary content of phenylalanine prescribed at age 5 $(\mathrm{mg} / \mathrm{kg} /$ day $)$, and plasma/blood phenylalanine control. In addition, permission was requested from families for genotyping for mutational analysis of the phenylalanine hydroxylase gene. A few of these variables will be explained in more detail.

IOS AT 8, 14, AND 18 YEARS OF AGE

Intelligence testing was carried out on patients using prescribed tests at set ages $(8,14,18$ years). The "Wechsler intelligence scale for children" (WISC) or revised WISC (WISC-R) was used at 8 and 14 years, the "Wechsler adult intelligence scale" (WAIS) or the revised WAIS (WAIS-R) was used at 18 years of age. Verbal, performance, and full scale scores were recorded. The results were expressed as standard deviations from the population norms (IQSDS) and adjusted for long term secular trends using formulae described by Smith and Beasley $^{2123}$ for full scale IQ. Population norms were estimated using results of a cross sectional analysis of population IQ trends of white Americans by Flynn ${ }^{37}$; ; Flynn's analysis has been shown to be applicable to children in the UK. ${ }^{39}{ }^{40}$ In applying Flynn's analysis to longitudinal data, it was assumed that individuals as well as populations show rises in IQ of 0.3 points each year and that the trends were the same for all tests used. In so doing, it is not possible to exclude a small, systematic error relating to change in absolute terms ${ }^{23}$; however, the method is suitable for assessing change in intellectual outome in relative terms within the patient group. Tests carried out within 9 months of 8 th, 14 th, or 18 th birthdays were included.

SOCIAL CLASS

Social class was assigned according to the Registrar General's classification $1980 .^{41}$

\section{GENOTYPE/PREDICTED RESIDUAL ENZYME}

ACTIVITY

Since 1994, automated sequencing has been used to detect the spectrum of mutations present in our phenylketonuria and hyperphenylalaninaemia population. ${ }^{42}{ }^{43}$ Genotype was available on at least one sibling in a family; parents were also tested. The genotype of all affected siblings from the same family was then assumed to be the same. The phenylalanine hydroxylase residual enzyme activity of many mutations has been measured in vitro by various authors; however, this value is not known for all mutations. The PRA of each patient was calculated as the arithmetic mean of the residual enzyme activities (in vitro) of the two mutant alleles where these values were known ${ }^{27-29}{ }^{34}$ (table 1 ).
Table 1 Phenylalanine hydroxylase mutations with corresponding in vitro predicted residual enzyme activities (PRA) used for subsequent analysis

\begin{tabular}{ll}
\hline Mutation & $\begin{array}{l}\text { Activity } \\
\text { (\% of normal) }\end{array}$ \\
\hline R243X, R252W, R408W, F299C, & \\
IVS12nt1, IVS10nt546 & 0 \\
E280K & 3 \\
R158Q & 10 \\
I65T,L348V,R261Q & 30 \\
Y414C & 50 \\
R408Q & 55 \\
\hline
\end{tabular}

PLASMA/BLOOD PHENYLALANINE CONTROL Plasma/blood phenylalanine control was scored for 0-8, 8-14, and 8-18 years.

In those under 8 years of age, all Guthrie results (carried out at least monthly) were considered once the blood phenylalanine concentration had fallen to $500 \mu \mathrm{mol} /$ litre or less after commencement of dietary treatment. Phenylalanine concentrations $125-500 \mu \mathrm{mol} /$ litre were considered good control. The proportion of results between 125 and $500 \mu \mathrm{mol} /$ litre was calculated and a score given as follows: 1, $75-100 \%$; 2, 50-74\%; 3, 25-49\%; and 4, $0-24 \%$. An arithmetic mean phenylalanine concentration could not be calculated because some results fell outside the limits of sensitivity (low and high) of the Guthrie assay.

In this cohort of patients, diet was relaxed after the age of 8 years (1970s to early 1990s). Between the ages of 8 and 14 years and 8 and 18 years, phenylalanine control was measured for those on whom PRA could be calculated (see above). This was the mean of twice yearly plasma phenylalanine concentrations from amino acid analysis. Where a patient had more than two results in the year, the results used were those obtained nearest to the birthday visit and six months after that date.

\section{STATISTICS}

Associations between PRA, phenylalanine concentrations, and phenylalanine intake were initially assessed with Spearman's rank correlation coefficients $\left(r_{\mathrm{s}}\right)$. The mean IQ-SDS at different ages were compared with normal values using the one sample $t$ test. Changes in IQ-SDS were assessed using the paired samples $t$ test. Comparisons of the mean IQ-SDS (and mean changes in IQ-SDS) between subgroups of children were obtained using either the independent samples $t$ test or one way analysis of variance. Changes in IQ-SDS were initially examined in relation to PRA by simple regression analysis. Although the IQ results in this study were adjusted for age and sex to standard deviation scores (IQ-SDS), concerns remained about a possible lack of comparability between IQ assessments at different ages, particularly for the comparison of 8 and 18 year IQ results when different tests were used. For this reason analyses of the relation between change in IQ-SDS and PRA were repeated using multiple regression with IQSDS at age 14 or 18 years as the response variable and IQ-SDS at age 8 years as a covariate; in addition to PRA, levels of control both before and after dietary relaxation were included as predictor variables 
Table 2 Mutation frequency in 100 patients genotyped

\begin{tabular}{ll}
\hline Mutation & Frequency (\%) \\
\hline R408W & $57(28.5)$ \\
I65T & $42(21.0)$ \\
F39L & $17(8.5)$ \\
Y414C & $12(6.0)$ \\
L348V, R408Q & $10(5.0)^{\star}$ \\
F299C & $9(4.5)^{\star}$ \\
R243X, IVS12nt1 & $5(2.5)^{\star}$ \\
G46S & $4(2.0)^{\star}$ \\
E280K, S67P, T380M & $3(1.5)^{\star}$ \\
L249F, L333F, R241L, R252W, R243Q & $2(1.0)^{\star}$ \\
S273F, A309V, IVSIOnt546, R158Q, & \\
A309D, IVS10nt554, A300V, R261Q, & \\
S349P, unidentified & $1(0.5)^{\star}$ \\
\hline
\end{tabular}

^Frequency for each mutation in this group.

\section{Results}

POPULATION STUDIED

There were 125 patients, 64 boys and 61 girls (all white), who were born between 1969 and 1986. Sixty seven per cent were from families where the head of the household was in a manual occupation at the time of diagnosis.

One hundred and eleven patients (93\%) were diagnosed at $\leqslant 21$ days of age. (There were six patients for whom this information was not available.) The remaining eight were diagnosed between 24 and 56 days; the reason for the delay was that they were mildly affected patients who were monitored by Guthrie test until phenylalanine concentration increased to a value requiring therapeutic intervention, at which stage a venous sample was taken. The time from birth until the whole blood (Guthrie) phenylalanine concentration fell to $<500 \mu \mathrm{mol} /$ litre ranged from nine to 63 (median, 21) days

Permission was obtained for genotyping in 100 patients; the remainder failed to respond to the request. Forty six different genotypes were found in this group of patients, the most common being I65T/R408W (10\%), R408W/ R408W (9\%), I65T/Y414C (7\%), and I65T/ I65T $(6 \%)$. There were 27 different alleles of which R408W (28.5\%), I65T (21\%), F39L $(8.5 \%)$, and Y414C $(6 \%)$ were the most common (table 2).

PHENYLALANINE CONCENTRATIONS AT

DIAGNOSIS, PHENYLALANINE INTAKE AT 5 YEARS, AND PHENYLALANINE CONTROL IN THE FIRST 8

YEARS WITH RESPECT TO PRA

PRA was calculated for 64 patients $(64 \%$ of those genotyped); PRA values were not available for the mutations found in the remaining patients at the time of analysis.

In the patient group, plasma phenylalanine concentrations at diagnosis ranged from 212 to

Table 3 Change in verbal, performance, and full scale IQ standard deviation scores $(I Q-S D S)$ between 8 and 14 years and 8 and 18 years

\begin{tabular}{llc}
\hline & Change in IQ-SDS $(95 \%$ CI) & p Value \\
\hline 8-14 years $(\mathrm{n}=72)$ & $-0.54(-0.73$ to -0.36$)$ & $<0.001$ \\
$\quad$ Verbal & $-0.16(-0.35$ to 0.04$)$ & 0.11 \\
Performance & $-0.34(-0.51$ to -0.18$)$ & $<0.001$ \\
Full scale & $-0.59(-0.82$ to -0.36$)$ & $<0.001$ \\
8-18 years $(\mathrm{n}=48)$ & $-0.16(-0.34$ to 0.03$)$ & 0.10 \\
Verbal & $-0.38(-0.58$ to -0.19$)$ & $<0.001$ \\
Performance & Full scale &
\end{tabular}

Scores are expressed as mean (95\% confidence interval).

^Paired samples $t$ test.
4750 (median, 1945) $\mu \mathrm{mol} /$ litre (excluding siblings who were diagnosed early because of the known family history). There was a negative correlation between PRA and plasma phenylalanine concentrations at diagnosis, excluding siblings $\quad\left(\mathrm{n}=42 ; \quad r_{\mathrm{s}}=-0.53\right.$; $\mathrm{p}<0.001$ ).

Phenylalanine intake prescribed at 5 years ranged from 6.9 to 121.0 (median, 17.1) $\mathrm{mg}$ phenylalanine/kg body weight/day. There was a positive correlation between PRA and phenylalanine intake at 5 years $\left(\mathrm{n}=63 ; r_{\mathrm{s}}=0.63\right.$; $\mathrm{p}<0.001$ ); there was also a negative correlation between plasma phenylalanine concentration at diagnosis and prescribed phenylalanine intake at 5 years $\left(\mathrm{n}=77 ; \quad r_{\mathrm{s}}=-0.44\right.$; $\mathrm{p}<0.001)$.

Phenylalanine control in the first 8 years was categorised into groups where 1 was best control and 4 was worst control (see Methods). There was a significant association between PRA and control in the first 8 years $(n=62$; $\left.r_{\mathrm{s}}=-0.38 ; \mathrm{p}=0.003\right)$.

INTELLECTUAL OUTCOME $I Q-S D S$ at 8,14 , and 18 years of age

IQ-SDS at 8,14 , and 18 years of age were each significantly below normal $(\mathrm{p}<0.001)$. The mean full scale IQ-SDS was -0.79 (95\% confidence interval (CI), -1.01 to -0.57$)$ for 108 children examined at 8 years, $-1.05(95 \% \mathrm{CI}$, -1.32 to -0.78 ) for 76 children examined at 14 years, and -1.17 (95\% CI, -1.42 to -0.93$)$ for 51 children examined at 18 years. Similar deficits were seen for verbal and performance IQ-SDS (not shown). Sex had no effect on IQ-SDS but children of manual workers had consistently lower IQ scores than those of nonmanual workers; this was significant for verbal and full scale scores at 8 years of age and verbal scores at 14 years of age $(p<0.05)$ (results not shown). Significant change in verbal and full scale IQ-SDS occurred both between 8 and 14 years and 8 and 18 years (table 3 ).

Associations between IQ-SDS, phenylalanine control, and PRA

Of 112 patients who had blood phenylalanine concentrations available between 0 and 8 years, $18 \%$ of patients had results assigned to category 1 (best phenylalanine control), $47 \%$ to category $2,23 \%$ to category 3 , and $12 \%$ to category 4 (worst phenylalanine control). There was a significant association between phenylalanine control at $0-8$ years and IQ-SDS at both 8 and 14 years; the association was no longer significant for IQ-SDS at 18 years (table 4). Neither the change in IQ-SDS between 8 and 14 years nor the change between 8 and 18 years was significantly related to phenylalanine control in the first 8 years.

Dietary control was relaxed after 8 years. Mean plasma phenylalanine concentrations between 8 and 14 years ranged from 406 to 1623 ( $\mathrm{n}=43$; mean, 912; SD, 295) $\mu \mathrm{mol} /$ litre, whereas those between 8 and 18 years ranged from 567 to 1627 ( $\mathrm{n}=31$; mean, 1044; SD, 247) $\mu \mathrm{mol} /$ litre. There was a significant association between PRA and phenylalanine control between 8 and 14 years $\left(n=43 ; r_{\mathrm{s}}=-0.37\right.$; 
Table 4 Association between dietary control between 0 and 8 years and verbal, performance, and full scale IQ standard deviation scores (IQ-SDS) at 8, 14 , and 18 years

\begin{tabular}{|c|c|c|c|c|c|}
\hline & \multicolumn{4}{|l|}{ Category } & \multirow[b]{2}{*}{$p$ Value * } \\
\hline & 1 (best) & 2 & 3 & 4 (worst) & \\
\hline 8 years IQ-SDS & $(\mathrm{n}=15)$ & $(\mathrm{n}=51)$ & $(\mathrm{n}=25)$ & $(\mathrm{n}=13)$ & \\
\hline Verbal & $-0.22(-0.69$ to 0.24$)$ & $-0.26(-0.58$ to 0.06$)$ & $-1.05(-1.58$ to -0.52$)$ & $-1.11(-1.69$ to -0.53$)$ & 0.007 \\
\hline Performance & $-0.61(-0.95$ to -0.28$)$ & $-0.71(-1.02$ to -0.39$)$ & $-1.43(-1.88$ to -0.98$)$ & $-1.66(-2.04$ to -1.29$)$ & 0.001 \\
\hline Full Scale & $-0.39(-0.77$ to -0.01$)$ & $-0.47(-0.80$ to -0.15$)$ & $-1.32(-1.82$ to -0.82$)$ & $-1.47(-1.92$ to -1.01$)$ & 0.001 \\
\hline 14 years IQ-SDS & $(n=6)$ & $(\mathrm{n}=31)$ & $(\mathrm{n}=20)$ & $(\mathrm{n}=12)$ & \\
\hline Verbal & $-1.03(-2.36$ to 0.31$)$ & $-0.46(-0.91$ to -0.01$)$ & $-1.33(-1.82$ to -0.84$)$ & $-1.70(-2.15$ to -1.25$)$ & 0.006 \\
\hline Performance & $-0.61(-2.03$ to 0.81$)$ & $-0.67(-1.13$ to -0.21$)$ & $-1.36(-1.79$ to -0.92$)$ & $-1.72(-2.32$ to -1.11$)$ & 0.02 \\
\hline Full Scale & $-0.85(-2.29$ to 0.59$)$ & $-0.52(-0.99$ to -0.05$)$ & $-1.41(-1.85$ to -0.97$)$ & $-1.82(-2.34$ to -1.30$)$ & 0.004 \\
\hline 18 years IQ-SDS & $(n=2)$ & $(\mathrm{n}=21)$ & $(\mathrm{n}=14)$ & $(\mathrm{n}=10)$ & \\
\hline Verbal & $-1.57(-3.53$ to 0.40$)$ & $-0.91(-1.32$ to -0.51$)$ & $-1.06(-1.60$ to -0.52$)$ & $-1.49(-2.08$ to -0.90$)$ & 0.34 \\
\hline Performance & $-1.57(-9.89$ to 6.76$)$ & $-0.91(-1.30$ to -0.52$)$ & $-0.96(-1.61$ to -0.31$)$ & $-1.83(-2.28$ to -1.37$)$ & 0.06 \\
\hline Full Scale & $-1.64(-6.27$ to 3.00$)$ & $-0.94(-1.33$ to -0.55$)$ & $-1.09(-1.65$ to -0.53$)$ & $-1.72(-2.23$ to -1.20$)$ & 0.12 \\
\hline
\end{tabular}

Results are expressed as mean (95\% confidence interval).

Categories: 1, 75-100\% phenylalanine concentrations between 125 and $500 \mu \mathrm{mol} / \mathrm{litre} ; 2,50-74 \%$ phenylalanine concentrations between 125 and $500 \mu \mathrm{mol} / \mathrm{litre}$; 3 , $25-49 \%$ phenylalanine concentrations between 125 and $500 \mu \mathrm{mol} /$ litre; 4, 0-24\% phenylalanine concentrations between 125 and $500 \mu \mathrm{mol} /$ litre.

$\star$ One way analysis of variance.

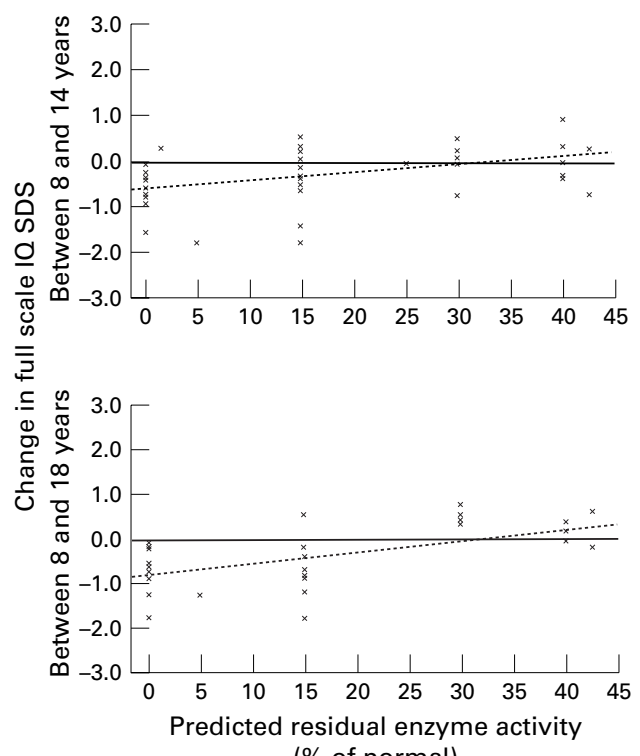

(\% of normal)

Figure 1 Association between change in full scale $I Q$ standard deviation scores (IQ-SDS) from 8-14 years and from 8-18 years and predicted residual enzyme activity (PRA). $8-14$ years $(n=42)$ : slope, $0.18 ; 95 \%$ confidence interval (CI), 0.06 to $0.31 ; p=0.005 .8-18$ years $(n=30)$ slope, 0.26; $95 \%$ CI, 0.11 to 0.42; $p=0.002$. Corresponding values for verbal and performance IQ-SDS were: slope, 0.16; $95 \%$ CI, 0.01 to $0.32 ; p=0.04$ and slope, $0.18 ; 95 \%$ CI, 0.02 to $0.34 ; p=0.03$ from $8-14$ years, respectively; and slope, $0.24 ; 95 \%$ CI, 0.07 to $0.42 ; p=0.007$ and slope, $0.19 ; 95 \%$ CI, 0.03 to $0.34 ; p=0.02$ from $8-18$ years, respectively. Slopes are scaled to represent the change in $I Q-S D S$ associated with a $10 \%$ increase in PRA

$\mathrm{p}=0.02)$ and PRA and control between 8 and 18 years $\left(\mathrm{n}=31 ; r_{\mathrm{s}}=-0.51 ; \mathrm{p}=0.003\right)$.

Although there was no significant association between IQ-SDS at 8,14, and 18 years of age and PRA, there was a significant association between the change in IQ-SDS and PRA, both between 8 and 14 years and 8 and 18 years (fig 1).

Table 5 summarises the multiple regression analysis of full scale IQ-SDS at 14 and 18 years in relation to PRA and phenylalanine control. Coefficients for PRA have been scaled to represent the difference in IQ-SDS associated with an increase in PRA of $10 \%$ of the normal value, whereas coefficients for control after the age of 8 years have been scaled to represent the difference in IQ-SDS associated with a worsening in phenylalanine concentrations of $100 \mu \mathrm{mol} /$ litre. Both the 14 year and 18 year analyses suggest that PRA is an important predictor of IQ-SDS after adjustment for phenylalanine control up to and after the age of 8 years. The coefficients indicate that each $10 \%$ increase in PRA is associated with a 0.15 higher IQ-SDS at each age.

\section{Discussion}

The fact that 46 different genotypes were found in this patient group meant that it was impossible to consider directly the effect of a specific genotype on intellectual outcome; others who have attempted to do this in either treated or untreated patients have not shown a simple association. ${ }^{35}{ }^{36}$ The method used to circumvent this problem was to express genotypes as the activities of the mutant enzymes, measured under in vitro conditions and termed predicted residual activity (PRA). It is recognised that this ${ }^{27}{ }^{28}$ and other ${ }^{44}$ methodologies all have some limitation when extrapolated to the in vivo condition. It was assumed that affected

Table 5 Regression coefficients for potential predictors of full scale IQ standard deviation scores (IQ-SDS) at 14 and 18 years

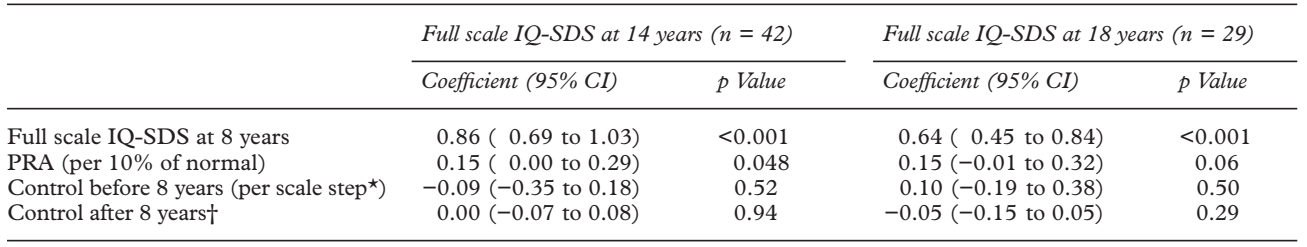

*Proportion of phenylalanine results between 125 and $500 \mu \mathrm{mol} / \mathrm{litre}$ scored as: $1,75-100 \% ; 2,50-74 \%$; 3, 25-49\%; 4, 0-24\% †For each $100 \mu \mathrm{mol} /$ litre increase in phenylalanine. 
siblings from the same family have the same genotype, an assumption that was considered safe because parents were also genotyped; this avoided the possibility of three mutant alleles, one encoding mild hyperphenylalaninaemia, occurring within one family, as has been reported previously. ${ }^{32}$ 45-48 All of the patients were diagnosed and treated early, and phenylalanine concentrations fell rapidly into the therapeutic range (median, 21 days after birth). Until the early 1990s, it was policy to relax the diet at the age of 8 years, and this is reflected in the plasma phenylalanine concentrations after this age. The associations between PRA and plasma phenylalanine concentration at diagnosis, ${ }^{27-29} 34$ and between PRA and prescribed phenylalanine intake at 5 years of age, ${ }^{27}$ which have been described previously, were confirmed in our study. The fact that mean IQ results were significantly below normal is also in keeping with previous studies. $^{1-3} 2123$

Change in IQ-SDS was calculated as the difference between the 14 or 18 year results and the 8 year results and was found to be significant for verbal and full scale IQ-SDS. The limitations of this calculation have been detailed above; the multiple regression approach also takes into account some of the concerns about the validity of IQ changes. The results show that not all patients deteriorated intellectually when diet was relaxed after 8 years, and are in keeping with those of Waisbren and colleagues who, using absolute IQ results, found that $40 \%$ of those in their sample population gained IQ points or maintained their IQ value after discontinuation of diet at 5 years of age. ${ }^{18}$ In the present study, patients with a higher PRA were less likely to deteriorate intellectually and some even improved; this is most apparent in those with a PRA $\geqslant 25 \%$ of normal values (genotypes R408Q/R408Q, L348V/R408Q, I65T/Y414C, I65T/L348V, and I65T/I65T). Simple regression analysis has confirmed an association between PRA and change in IQ-SDS. Multiple regression analysis of IQ-SDS at 14 and 18 years, using 8 year results as covariates, showed that PRA was an important predictor.

In a study of 64 patients still under strict dietary control, no correlation was found between PRA and IQ (WISC-R) at the age of 9 years; however, there was an association between low PRA and high fluctuations in phenylalanine concentrations. ${ }^{34}$ In another study of 55 older, untreated patients, a simple association was not found between PRA and IQ (assessed by the Binet test at undisclosed ages). ${ }^{31}$ However, both these studies measured IQ at a single point in time. We also found no significant association between PRA and IQSDS when assessed at a single time point. The lack of association could, in part, be the result of both differences in intrinsic intellectual endowment and other genetic interactions in the metabolism of phenylalanine, in addition to that exerted by phenylalanine hydroxylase. ${ }^{31-33}$ In patients with phenylketonuria and hyperphenylalaninaemia with different genotypes, longitudinal measurements evaluating change in IQ in the same individual render less significant the roles played by other genes and intrinsic intellectual endowment. This might explain why a strong association was found between PRA and change in IQ-SDS between 8 and 18 years.

It is clear that there is a complex relation between PRA, dietary management, and IQ. An association between PRA and control both before and after dietary relaxation was found in our study. However, Burgard et al found no relation between PRA and control. ${ }^{34}$ Their patients were all under good control, as measured by the mean of the first nine yearly phenylalanine medians. It is of interest that in our study the effects of control before 8 years of age were seen on IQ-SDS at both 8 and 14 years but no longer at 18 years of age.

This study has shown that patients with a PRA of $25 \%$ or greater are more likely to maintain or gain IQ points after relaxation of diet in the years 8-18 than those with a lower PRA. If further prospective and multicentre studies confirm these findings, the importance of genotype, PRA, and strict dietary control after the age of 8 years will need to be re-evaluated.

1 Smith I, Beasley MG, Ades AE. Intelligence and quality of dietary treatment in phenylketonuria. Arch Dis Child 1990;65:472-8

2 Azen C, Koch R, Friedman E, Wenz E, Fishler K. Summary of findings from the United States collaborative study of children treated for phenylketonuria. Eur $\mathcal{F}$ Pediatr 1996; 155(suppl 1):S29-32.

3 Burgard P, Schmidt E, Rupp A, Schneider W, Bremer HJ. Burgard P, Schmidt E, Rupp A, Schneider W, Bremer HJ.
Intellectual development of the patients of the German collaborative study of children treated for phenylketonuria. Eur F Pediatr 1996;155(suppl 1):S33-8.

4 Scheibenreiter S, Tiefenthaler M, Hinteregger V, et al. Austrian report on longitudinal outcome in phenylketonuria Eur F Pediatr 1996;155(suppl 1):S45-9.

5 Schuler A, Somogyi Cs, Tôrös I, et al. A longitudinal study of phenylketonuria based on the data of the Budapest screening center. Eur F Pediatr 1996;155(suppl 1):S50-2.

6 Cabalska MB, Nowaczewska I, Sendecka E, Zorska K. Longitudinal study on early diagnosis and treatment of phenylketonuria in Poland. Eur $\mathcal{F}$ Pediatr 1996;155(suppl 1):S53-5.

7 Zeman J, Pijackova A, Behulova J, Urge O, Saligova D, Hyanek J. Intellectual and school performance in adolescents with phenylketonuria according to their dietary compliance. The Czech-Slovak collaborative study. Eur f Pedipliance. The Czech-Slovak co

8 Cechák P, Hejcmanová L, Rupp A. Long-term follow-up of patients treated for phenylketonuria (PKU). Results from the Prague PKU center. Eur f Pediatr 1996;155(suppl 1): S59-63.

9 Rey F, Abadie V, Plainguet F, Rey J. Long-term follow up of patients with classical phenylketonuria after diet relaxation at 5 years of age. The Paris study. Eur $\mathcal{f}$ Pediatr 1996;155(suppl 1):S39-44.

10 Smith I, Lobascher ME, Stevenson JE, et al. Effect of stopping low-phenylalanine diet on intellectual progress of children with phenylketonuria. BMF 1978;2:723-6.

11 Schuett VE, Gurda RF, Brown ES. Diet discontinuation policies and practices of PKU clinics in the United States. Am f Public Health 1980;70:498-503.

12 Waisbren SE, Schnell RR, Levy HL. Diet termination in children with phenylketonuria; a review of psychological children with phenylketonuria; a review of psychological Dis 1980;3:149-53.

13 Seashore MR, Friedman E, Novelly RA, Bapat V. Loss of intellectual function in children with phenylketonuria after relaxation of dietary phenylalanine restriction. Pediatrics 1985;75:226-32.

14 Holtzman NA, Kronmal RA, van Doorninck W, Azen C, Koch R. Effect of age at loss of dietary control on intellectual performance and behavior of children with phenylketonuria. N Engl F Med 1986;314:593-8.

15 Barabas G, Matthews WS. Discontinuing the PKU diet. Pediatrics 1987;77:434-5.

16 Saudubray JM, Rey F, Ogier H, et al. Intellectual and school performances in early-treated classical PKU patients. The performances in early-treated collaborative study. Eur $\mathcal{f}$ Pediatr 1987;46.suppl 1):A20-2.

17 Koch R, Azen CG, Hurst N, Gross Friedman E, Fishler K. The effects of diet discontinuation in children with phenylketonuria. Eur f Pediatr 1987;146(suppl 1):A12-16. 
18 Waisbren SE, Mahon BE, Schnell RR. Levy HL. Predictors of intelligence quotient and intelligence quotient change in persons treated for phenylketonuria early in life. Pediatrics

9 Schmidt H, Mahle M, Michel U, Pietz J. Continuation vs discontinuation of low-phenylalanine diet in PKU adolescents. Eur f Pediatr 1987;146(suppl 1):A17-19.

20 Azen CG, Koch R, Gross Friedman E, et al. Intellectual development in 12-year-old children treated for phenylketonuria. Am F Dis Child 1991;145:35-9.

21 Smith I, Beasley MG, Ades AE. Effect on intelligence of relaxing the low phenylalanine diet in phenylketonuria. Arch Dis Child 1991;66:311-16.

22 Potocnik U, Widhalm K. Long-term follow-up of children with classical phenylketonuria after diet discontinuation: a review. F Am Coll Nutr 1994;13:232-6.

23 Beasley MG, Costello PM, Smith I. Outcome of treatment in young adults with phenylketonuria detected by routine 1994;87:155-60.

24 Levy HL, Waisbren SE. PKU in adolescents: rationale and psychosocial factors in diet continuation. Acta Paediatr psychosocial factors
Suppl 1994;407:92-7.

25 Schmidt H, Burgard P, Pietz J, Rupp A. Intelligence and professional career in young adults treated early for phenylketonuria. Eur $\mathcal{F}$ Pediatr 1996;155(suppl 1):S97100.

26 Cabalska B, Zorska K, Nowaczewska I, et al. Termination of dietary treatment in phenylketonuria. In: Naruse H, Irie $M$ eds. Neonatal screening. Amsterdam: Excerpta Medica 1983:219-24.

27 Okano Y, Eisensmith RC, Güttler F, et al. Molecular basis of phenotypic heterogeneity in phenylketonuria. $N$ Engl f Med 1991;324:1232-8.

28 Svensson E, von Döbeln U, Eisensmith RC, Hagenfeldt L, Woo SLC. Relation between genotype and phenotype in Swedish phenylketonuria and hyperphenylalaninemia patients. Eur f Pediatr 1993;152:132-9.

29 Eisensmith RC, Martinez DR, Kuzmin AI, et al. Molecular basis of phenylketonuria and a correlation between basis of phenylketonuria and a correlation between genotype and phenotype in a heterogeneous

30 Güttler F, Guldberg P. The influence of mutations on enzyme activity and phenylalanine tolerance in phenylalanine hydroxylase deficiency. Eur $\mathcal{F}$ Pediatr 1996 155(suppl 1):S6-10

31 Ramus SJ, Forrest SM, Pitt DB, Saleeba JA, Cotton RGH Comparison of genotype and intellectual phenotype in untreated PKU patients. F Med Genet 1993;30:401-5.

32 Tyfield LA, Zschocke J, Stephenson A, et al. Discordant phenylketonuria phenotypes in one family: the relationship between genotype and clinical outcome is a function of multiple effects. F Med Genet 1995;32:867-70.

33 Tyfield LA. Phenylketonuria in Britain: genetic analysis gives a historical perspective of the disorder but will it pre- dict the future for affected individuals? 7 Clin Pathol: $M o l$ Pathol 1997;50:M169-74.

34 Burgard P, Rupp A, Konecki DS, Trefz FK, Schmidt H, Lichter-Konecki U. Phenylalanine hydroxylase genotypes, predicted residual enzyme activity and phenotypic parameters of diagnosis and treatment of phenylketonuria. Eur $\mathcal{F}$ Pediatr 1996;155(suppl 1):S11-15.

35 Koch R, Fishler K, Azen C, Guldberg P, Güttler F. The relationship of genotype to phenotype in phenylalanine hydroxylase deficiency. Biochem Mol Med 1997;60:92-101.

36 Güttler F, Guldberg P, Henriksen KF. Mutation genotype of mentally retarded patients with phenylketonuria. Developmental Brain Dysfunction 1993;6:92-6.

37 Flynn J. The mean IQ of Americans: massive gains 1932 to 1978. Psychol Bull 1984;95:29-51.

38 Flynn J. Massive IQ gains in 14 nations: what IQ tests really measure. Psychol Bull 1987;101:171-91.

39 Fuggle PW, Tokar S, Grant DB, Smith I. Rising IQ scores in British children: recent evidence. F Child Psychol Psychiatry 1992;33:1241-7.

40 Lynn R, Hampson SL, Mullineux JC. A long-term increase in the fluid intelligence of English children. Nature 1987;328:797.

41 Office of Population Censuses and Surveys. Classification of occupations. London: HMSO, 1980.

42 Zschocke J, Graham CA, Stewart FJ, Carson DJ, Nevin NC. Automated sequencing detects all mutations in Northern Irish patients with phenylketonuria and mild hyperphenylalaninaemia. Acta Paediatr Suppl 1994;407:37-8.

43 Zschocke J, Graham CA, Carson DJ, Nevin NC. Phenylketonuria mutation analysis in Northern Ireland: a rapid stepwise approach. Am F Hum Genet 1995;57:1311-17.

44 Guldberg P, Rey, F, Zschocke J, et al. A European multicenter study of phenylalanine hydroxylase deficiency: classification of 105 mutations and a general system for genotype-based prediction of metabolic phenotype. Am $\mathcal{F}$ Hum Genet 1998;63:71-9.

45 Güttler F, Guldberg P. Mutations in the phenylalanine hydroxylase gene: genetic determinants for the phenotypic hydroxylase gene: genetic determinants for the phenotypic
variability of hyperphenylalaninemia. Acta Paediatr Suppl 1994;407:49-56.

46 Ledley FD, Levy HL, Woo SLC. Molecular analysis of the inheritance of phenylketonuria and mild hyperphenylalaninema in families with both disorders. $N$ Engl f Med 1986;314:1276-80.

47 Avigad S, Kleiman S, Weinstein M, et al. Compound heterozygosity in non-phenylketonuria hyperphenylalaninemia: the contribution of mutations for classical phenylketonuria. Am f Hum Genet 1991;49:393-9.

48 Guldberg P, Levy HL, Koch R, et al. Mutation analysis in families with discordant phenotypes of phenylalanine hydroxylase deficiency. Inheritance and expression of the hyperphenylalaninaemias. F Inherit Metab Dis 1994;17: $645-51$. 